\title{
Review Article \\ The Clinical Value of Oxymatrine in Preventing Lamivudine Induced YMDD Mutation: A Meta-Analysis
}

\author{
Min He, Yu Wu, Mengmeng Wang, Wenwen Chen, Weian Yuan, and Jian Jiang \\ Department of Clinical Pharmacology, Shuguang Hospital Affiliated to Shanghai University of TCM, Shanghai 201203, China \\ Correspondence should be addressed to Weian Yuan; weian_1980@163.com and Jian Jiang; jiangjiansg@163.com
}

Received 25 May 2015; Revised 22 July 2015; Accepted 28 July 2015

Academic Editor: Qihe Xu

Copyright (C) 2015 Min He et al. This is an open access article distributed under the Creative Commons Attribution License, which permits unrestricted use, distribution, and reproduction in any medium, provided the original work is properly cited.

\begin{abstract}
Oxymatrine (OMTR) is widely used for the treatment of chronic hepatitis B (CHB) in China. Several reports revealed that combination of OMTR and lamivudine reduced the incidence of tyrosine- (Y-) methionine- (M-) aspartic acid- (D-) aspartic acid (D) (YMDD) mutations in CHB patients. The aim of this study was to evaluate the clinical value of oxymatrine in preventing lamivudine induced YMDD mutation using meta-analysis of data from published randomized controlled trials (RCTs) and to provide some useful information for clinical treatment and future research of YMDD mutation. The Cochrane Central Register of Controlled Trials, Medline, Science Citation Index, EMBASE, China National Knowledge Infrastructure, Wanfang Database, and China Biomedical Database were searched to identify RCTs that evaluated the incidence of YMDD-motif mutation to lamivudine therapy and lamivudine plus OMTR therapies in CHB patients. Data analysis was carried out with the use of RevMan 5.3.2. The literature search yielded 324 studies, and 16 RCTs matched the selection criteria. Overall, the incidence of YMDD mutation was significantly lower in patients treated with lamivudine plus OMTR than in patients treated with lamivudine alone (11.14\% versus 28.18\%; RR: 0.41; 95\% CI: 0.33-0.52; $p<0.05$ ). The exact outcome needs to perform rigorously designed, multicenter, and large randomized controlled trials.
\end{abstract}

\section{Introduction}

Chronic infection of hepatitis B virus (HBV) poses serious public health problems because of the high prevalence rates in many parts of the world and adverse long-term clinical outcomes, including premature deaths from hepatic decompensation, cirrhosis, and hepatocellular carcinoma [1]. The majority of countries in Asia have low-income economies and are at high endemicity of $\mathrm{HBV}$ infection [2]. It is estimated in China that there are 120 million chronically infected carriers; up to 12 million people suffer from chronic hepatitis B (CHB), and about 300,000 people die each year [3].

Currently nucleoside/nucleotide analogues (NAs) are the main available treatments for CHB. The approved NAs include lamivudine, telbivudine, adefovir, tenofovir, and entecavir [1]. However, treatment of chronic HBV infection is a complex task, and HBV drug resistance is one of the most significant factors in treatment failure for CHB [4]. Selective pressure from either the immune response or the use of NA in antiviral therapy could be driving the emergence of HBV drug-resistance mutants [4-6]. Drug-resistance mutations occur in the reverse transcriptase region of the HBV polymerase gene and spontaneously arise during viral replication. These mutations alter the hepatitis B surface (HBs) protein and in some cases reduce binding to HBs antibodies, as well as reducing susceptibility of HBV to NA. The spread of NAresistant HBV may impact the efficacy of antiviral treatment and hepatitis $B$ immunization programmers $[5,6]$. The long-term benefits of antiviral treatment are limited by the resistance of HBV [4]. Moreover, since the number of HBV antiviral drugs is limited, transmission of mutant virus is of particular importance for HBV infection as mutations that confer cross-reactivity can leave patients with few therapy options.

The tyrosine-methionine-aspartate-aspartate (YMDD) is one of the most common HBV drug-resistance mutations, which is in the catalytic domain C of viral DNA polymerase [6]. The primary resistance mutations result in the replacement of the methionine by valine, isoleucine, or occasionally serine and are designated as $\mathrm{rtM} 204 \mathrm{~V} / \mathrm{I}[4,6]$. 
These mutations (rtM204V/I) confer cross-resistance to lamivudine, telbivudine, and other members that belong to the L-nucleoside structural group such as emtricitabine and clevudine and reduce susceptibility to entecavir [4-8]. Moreover, it caused significant reduction in the antigenicity of immune-escaped HBsAg [9]. YMDD mutations are also an independent risk factor for HCC in liver cirrhosis patients [10]. YMDD mutations play an important role in the chronic hepatitis B management [4-6].

Sophora alopecuroides L. has been widely used for the treatment of liver disease in China. Oxymatrine (OMTR) (MW: 264.31) is one of the most pharmacologically active components in Sophora alopecuroides L. and had also been found to be capable of inhibiting $\mathrm{HBV}$ and relieving hepatic fibrosis [11-16]. It has been approved for the treatment of hepatitis B by the State Food and Drug Administration of China and is listed as one of the recommended anti-HBV drugs in the Guideline for Prevention and Treatment of CHB jointly proposed by the Chinese Society of Hepatology and the Chinese Society of Infectious Diseases. The rate of YMDD mutations is $24 \%$ after 1 year of lamivudine treatment [17]. Several reports revealed that combination of OMTR and lamivudine reduced the incidence of YMDD mutations caused by lamivudine. However, convincing evidence of lamivudine plus OMTR therapies is still needed. In addition, these studies, published in Chinese, cannot be accessed by non-Chinese speaking scientists.

The aim of this study was to evaluate the clinical value of oxymatrine in preventing lamivudine induced YMDD mutation using meta-analysis of data from published randomized controlled trials (RCTs) and to provide some useful information for clinical treatment and future research of YMDD mutation.

\section{Materials and Methods}

2.1. Eligibility Criteria. The inclusion criteria were the following: (i) Clinical diagnosis must meet the diagnostic criteria for $\mathrm{CHB}$ (Chinese Commission of Infectious and Parasitic Diseases, Viral Hepatitis Prevention and Treatment Programs); (ii) the included RCT studies were designed to compare the therapeutic effects of lamivudine therapy or lamivudine plus OMTR therapies in CHB patients; patients coinfected with other viral infections (HAV, HCV, HDV, and $\mathrm{HEV}$ ) or hepatic cellular cancers were excluded; (iii) patients were treated for at least 48 weeks. Reports of duplicated studies were excluded by examining the author list, parent institution, sample size, and results.

2.2. Outcome Measure. The primary outcome was the incidence of YMDD mutation, and other measures included the end-of-treatment viral response (ETVR), alanine transaminase (ALT) normalization, HBeAg loss, HBeAg seroconversion, and occurrence of adverse events. The incidence of YMDD mutation was defined as detectable YMDD mutation by a sensitive test after treatment. ETVR was defined as undetectable HBV DNA at the end of treatment.
2.3. Information Sources and Searches. A search of the literature was conducted for studies that reported the therapeutic effects of lamivudine with or without OMTR therapies in CHB patients. The Cochrane Central Register of Controlled Trials, Medline, Science Citation Index, EMBASE, China National Knowledge Infrastructure, Wanfang Database, and China Biomedical Database were searched to identify RCTs published in the field of antiviral therapy for CHB. All the databases above were searched from their date of inception onwards until June 1, 2015, and irrespective of language or publication status. The keywords used in the literature searches included the following: chronic hepatitis B, hepatitis B virus, oxymatrine, lamivudine, YMDD, rtM204I, rtM204V, treatment, and trial.

2.4. Study Selection and Data Collection. Two authors (Min $\mathrm{He}$ and $\mathrm{Yu} \mathrm{Wu}$ ) independently screened titles and abstracts for potential eligibility and the full texts for final eligibility. We extracted the data from the included trials independently for quantitative analyses, and any disagreement was subsequently resolved by discussion.

2.5. Assessment of Risk of Bias in Included Studies. Two authors (Mengmeng Wang and Wenwen Chen) independently assessed the risk of bias for each included randomised trial. Disagreements were resolved by discussion with Jian Jiang and Weian Yuan. We assessed the following domains [18].

\subsubsection{Allocation Sequence Generation}

(i) Low risk of bias: sequence generation was achieved using computer random number generation or a random number table. Drawing lots, tossing a coin, shuffling cards, and throwing dice are adequate if performed by an independent adjudicator.

(ii) Uncertain risk of bias: the trial was described as randomised, but the method of sequence generation was not specified.

(iii) High risk of bias: the sequence generation method is not, or may not be, random. Quasi-randomised studies, those using dates, names, or admittance numbers in order to allocate patients, are inadequate and will be excluded for the assessment of benefits but not for harm.

\subsubsection{Allocation Concealment}

(i) Low risk of bias: allocation was controlled by a central and independent randomization unit, sequentially numbered, opaque, and sealed envelopes or similar, so that intervention allocations could not have been foreseen in advance of, or during, enrolment.

(ii) Uncertain risk of bias: the trial was described as randomised but the method used to conceal the allocation was not described, so that intervention allocations may have been foreseen in advance of, or during, enrolment. 
TABLE 1: Characteristics of the trials included in the meta-analysis.

\begin{tabular}{|c|c|c|c|c|c|}
\hline References & $\begin{array}{c}\text { Sample size } \\
\text { (treatment/control) }\end{array}$ & $\begin{array}{c}\text { Gender } \\
\text { (male/female) }\end{array}$ & Age & $\begin{array}{c}\text { Treatment } \\
\text { duration } \\
\text { (weeks) }\end{array}$ & $\begin{array}{l}\text { YMDD mutation } \\
\text { (pretreatment) } \\
\text { (treatment/control) }\end{array}$ \\
\hline Chen and Yang (2010) [20] & $70 / 70$ & $82 / 58$ & $19 \sim 61$ & 52 & $0 / 0$ \\
\hline Ding and Hua (2010) [21] & $30 / 34^{\mathrm{a}}$ & $41 / 23$ & $18 \sim 49$ & 260 & $0 / 0$ \\
\hline Guo (2007) [22] & $36 / 34$ & $60 / 10$ & 38.5 & 52 & $0 / 0$ \\
\hline Guo et al. (2005) [23] & $132 / 64$ & $-1-$ & - & 52 & $0 / 0$ \\
\hline Hu and Zhao (2009) [24] & $20 / 20$ & $27 / 13$ & 31.25 & 52 & $0 / 0$ \\
\hline Huang (2007) [25] & $33 / 34$ & $52 / 15$ & $19 \sim 55$ & 56 & $0 / 0$ \\
\hline Huang et al. (2006) [26] & $87 / 70$ & $95 / 62$ & 39.1 & 52 & $0 / 0$ \\
\hline Li and Liang (2007) [27] & $34 / 41$ & $54 / 21$ & $18 \sim 58$ & 52 & $0 / 0$ \\
\hline Shen et al. (2005) [28] & $62 / 57$ & $-1-$ & $18 \sim 58$ & 104 & $0 / 0$ \\
\hline Sheng et al. (2006) [29] & $70 / 65^{\mathrm{a}}$ & $109 / 26$ & $18 \sim 65$ & $52 \sim 104$ & $0 / 0$ \\
\hline $\mathrm{Su}(2005)[30]$ & $30 / 30$ & $-1-$ & $34.89 \pm 11.13$ & 52 & $0 / 0$ \\
\hline Wang (2008) [31] & $64 / 64$ & $77 / 51$ & $18 \sim 54$ & 52 & $0 / 0$ \\
\hline Wang (2009) [32] & $31 / 34$ & $38 / 27$ & 50.1 & 48 & $0 / 0$ \\
\hline Wu et al. (2009) [33] & $50 / 50$ & $54 / 46$ & $22 \sim 62$ & 48 & $0 / 0$ \\
\hline Zhao et al. (2010) [34] & $40 / 43$ & $52 / 31$ & $16 \sim 62$ & 78 & $0 / 0$ \\
\hline Zhou (2009) [35] & $35 / 35$ & $55 / 15$ & $19 \sim 61$ & 52 & $0 / 0$ \\
\hline
\end{tabular}

${ }^{a}$ Patients did not complete detection of YMDD mutation and data is shown.

(iii) High risk of bias: the allocation sequence was known to the investigators who assigned participants or the study was quasi-randomised. Quasi-randomised studies will be excluded for the assessment of benefits but not for harm.

\subsubsection{Blinding}

(i) Low risk of bias: the trial was described as blinded, the parties were blinded, and the method of blinding was described, so that knowledge of allocation was adequately prevented during the trial.

(ii) Uncertain risk of bias: the trial was described as blinded, but the method of blinding was not described, so that knowledge of allocation was possible during the trial.

(iii) High risk of bias: the trial was not blinded, so that the allocation was known during the trial.

\subsubsection{Incomplete Outcome Data}

(i) Low risk of bias: the numbers and reasons for dropouts and withdrawals in all intervention groups were described or it was specified that there were no dropouts or withdrawals.

(ii) Uncertain risk of bias: the report gave the impression that there had been no dropouts or withdrawals, but this was not specifically stated.

(iii) High risk of bias: the numbers or reasons for dropouts and withdrawals were not described.

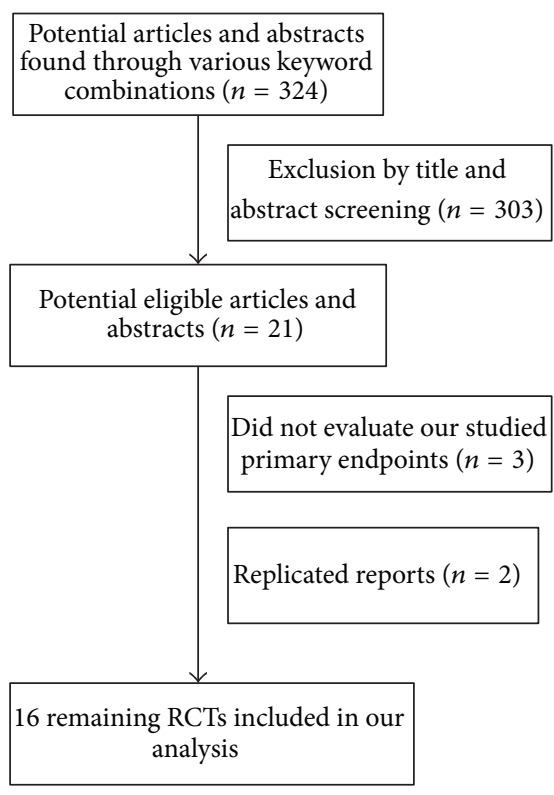

Figure 1: Analysis of the search results.

\subsubsection{Selective Outcome Reporting}

(i) Low risk of bias: predefined or clinically relevant and reasonably expected outcomes are reported on.

(ii) Uncertain risk of bias: not all predefined or clinically relevant and reasonably expected outcomes are reported on or are not reported fully, or it is unclear whether data on these outcomes were recorded or not. 
TABLE 2: Interventions of the trials included in the meta-analysis.

\begin{tabular}{|c|c|c|}
\hline \multirow{2}{*}{ References } & \multicolumn{2}{|l|}{ Intervention } \\
\hline & Treatment (OMTR plus lamivudine) & Control (lamivudine) \\
\hline Chen and Yang (2010) [20] & Lamivudine (100 mg once-daily), OMTR capsules (200 mg thrice-daily) & lamivudine (100 mg once-daily) \\
\hline Ding and Hua (2010) [21] & Lamivudine (100 mg once-daily), OMTR capsules (200 mg thrice-daily) & lamivudine (100 mg once-daily) \\
\hline Guo (2007) [22] & $\begin{array}{l}\text { Lamivudine ( } 100 \mathrm{mg} \text { once-daily), OMTR (beginning } 4 \text { weeks, OMTR } \\
\text { injection } 600 \mathrm{mg} \text { /day; the remaining weeks, OMTR capsules } 200 \mathrm{mg} \\
\text { thrice-daily) }\end{array}$ & lamivudine (100 mg once-daily) \\
\hline Guo et al. (2005) [23] & $\begin{array}{l}\text { Lamivudine ( } 100 \mathrm{mg} \text { once-daily), OMTR (beginning } 8 \text { weeks, OMTR } \\
\text { injection } 600 \mathrm{mg} \text { /day; the remaining } 26 \text { weeks, OMTR capsules } 200 \mathrm{mg} \\
\text { thrice-daily) }\end{array}$ & lamivudine (100 mg once-daily) \\
\hline Hu and Zhao (2009) [24] & Lamivudine (100 mg once-daily), OMTR capsules (200 mg thrice-daily) & lamivudine (100 mg once-daily) \\
\hline Huang (2007) [25] & $\begin{array}{l}\text { Lamivudine ( } 100 \mathrm{mg} \text { once-daily), OMTR capsules (beginning } 28 \text { weeks, } \\
200 \mathrm{mg} \text { thrice-daily) }\end{array}$ & lamivudine (100 mg once-daily) \\
\hline Huang et al. (2006) [26] & $\begin{array}{l}\text { Lamivudine ( } 100 \mathrm{mg} \text { once-daily), OMTR capsules (beginning } 26 \text { weeks, } \\
200 \mathrm{mg} \text { thrice-daily) }\end{array}$ & lamivudine (100 mg once-daily) \\
\hline Li and Liang (2007) [27] & Lamivudine (100 mg once-daily), OMTR capsules (200 mg thrice-daily) & lamivudine (100 mg once-daily) \\
\hline Shen et al. (2005) [28] & $\begin{array}{l}\text { Lamivudine ( } 100 \mathrm{mg} \text { once-daily), OMTR (beginning } 8 \text { weeks, OMTR } \\
\text { injection } 600 \mathrm{mg} / \text { day; the remaining } 18 \text { weeks, OMTR capsules } 200 \mathrm{mg} \\
\text { thrice-daily) }\end{array}$ & lamivudine (100 mg once-daily) \\
\hline Sheng et al. (2006) [29] & $\begin{array}{l}\text { Lamivudine ( } 100 \mathrm{mg} \text { once-daily), OMTR (at } 26 \text { weeks after lamivudine } \\
\text { treatment, OMTR injection } 600 \mathrm{mg} / \text { day, } 8 \text { weeks) }\end{array}$ & lamivudine (100 mg once-daily) \\
\hline $\mathrm{Su}(2005)[30]$ & $\begin{array}{l}\text { Lamivudine ( } 100 \mathrm{mg} \text { once-daily), OMTR (beginning } 13 \text { weeks, OMTR } \\
\text { injection } 600 \mathrm{mg} \text { /day; the remaining weeks, OMTR capsules } 100 \mathrm{mg} \\
\text { thrice-daily) }\end{array}$ & lamivudine (100 mg once-daily) \\
\hline Wang (2008) [31] & $\begin{array}{l}\text { Lamivudine ( } 100 \mathrm{mg} \text { once-daily), OMTR capsules (beginning } 26 \text { weeks, } \\
200 \mathrm{mg} \text { thrice-daily) }\end{array}$ & lamivudine (100 mg once-daily) \\
\hline Wang (2009) [32] & Lamivudine (100 mg once-daily), OMTR capsules (200 mg thrice-daily) & lamivudine (100 mg once-daily) \\
\hline Wu et al. (2009) [33] & $\begin{array}{l}\text { Lamivudine ( } 100 \mathrm{mg} \text { once-daily), OMTR capsules (beginning } 24 \text { weeks, } \\
200 \mathrm{mg} \text { thrice-daily) }\end{array}$ & lamivudine (100 mg once-daily) \\
\hline Zhao et al. (2010) [34] & $\begin{array}{l}\text { Lamivudine ( } 100 \mathrm{mg} \text { once-daily), OMTR capsules (beginning } 26 \text { weeks, } \\
200 \mathrm{mg} \text { thrice-daily) }\end{array}$ & lamivudine (100 mg once-daily) \\
\hline Zhou (2009) [35] & $\begin{array}{l}\text { Lamivudine ( } 100 \mathrm{mg} \text { once-daily), OMTR (beginning } 13 \text { weeks, OMTR } \\
\text { injection } 600 \mathrm{mg} / \text { day; the remaining weeks, OMTR capsules } 200 \mathrm{mg} \\
\text { thrice-daily) }\end{array}$ & lamivudine (100 mg once-daily) \\
\hline
\end{tabular}

OMTR: oxymatrine.

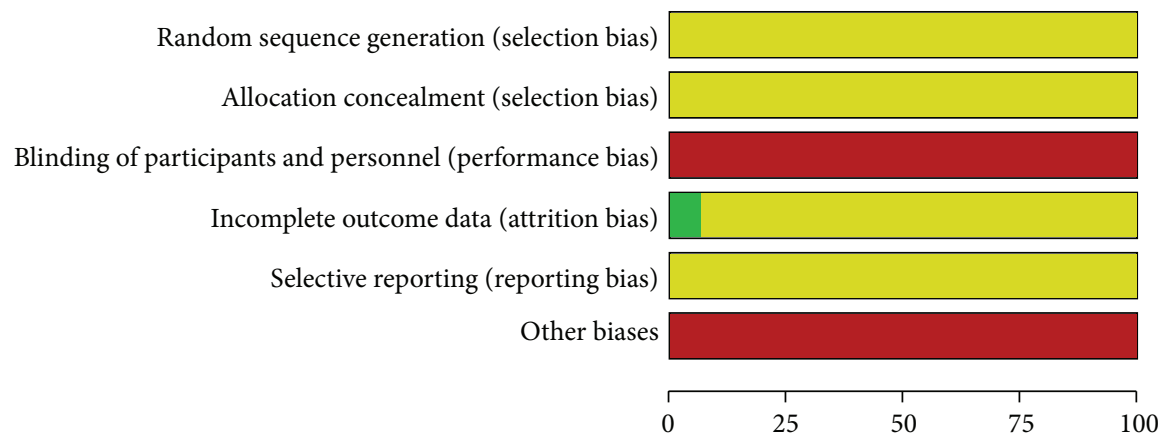

(\%)

Low risk of bias

$\square$ Unclear risk of bias

High risk of bias

FIGURE 2: Risk of bias graph: reviewing authors' judgements about each risk of bias item presented as percentages across all included studies. 
(iii) High risk of bias: one or more clinically relevant and reasonably expected outcomes were not reported on; data on these outcomes were likely to have been recorded.

\subsubsection{Other Biases}

(i) Low risk of bias: the trial appears to be free of other sources of bias (e.g., conflict of interests bias).

(ii) Uncertain risk of bias: there is insufficient information to assesswhether other sources of bias are present.

(iii) High risk of bias: it is likely that potential sources of bias related to specific design used, early termination due to some data-dependent process, lack of sample size or power calculation, or other bias risks are present.

Authors' judgements were based on the definitions of the above-listed domains, and trials with adequate assessments in all of the abovementioned bias risks domains were considered as having low risk of bias. Otherwise, a trial was considered with high risk of bias.

2.6. Assessment of Heterogeneity. We planned to use the Chisquared statistic to assess heterogeneity and $I$-square statistic to measure inconsistency [19].

2.7. Assessment of Publication Biases. We planned to use the funnel plot to investigate publication biases if there were more than ten included trials.

2.8. Statistical Analysis. Meta-analysis was performed using fixed effect or random effect methods, depending on the absence or presence of significant heterogeneity. We used the relative risk (RR) of the main dichotomous outcomes as the measure of efficacy. The 95\% confidence interval (CI) for the combined RR was also provided. The overall effect was tested using $z$ scores calculated by Fisher's $z$ transformation, with significance set at $p<0.05$. Data analysis was carried out with the use of Review Manager Software 5.3.2 (Cochrane Collaboration, Oxford, United Kingdom).

\section{Results}

3.1. Literature Search. Figure 1 shows the results of the study screen. The literature search yielded 324 studies, 16 of which matched the selection criteria [20-35]. The combined CHB patient total was 1569 .

3.2. Patient Characteristics and Study Quality. All RCTs included were published as full-length articles. The patients included in the sixteen trials were randomly assigned to accept lamivudine plus OMTR therapies or lamivudine therapy alone. Of the 1569 patients, 824 patients had therapy with lamivudine plus OMTR, and 745 patients had therapy with lamivudine alone. All studies were single-centre trials. The baseline characteristics of the sixteen included trials were summarized in Tables 1 and 2.
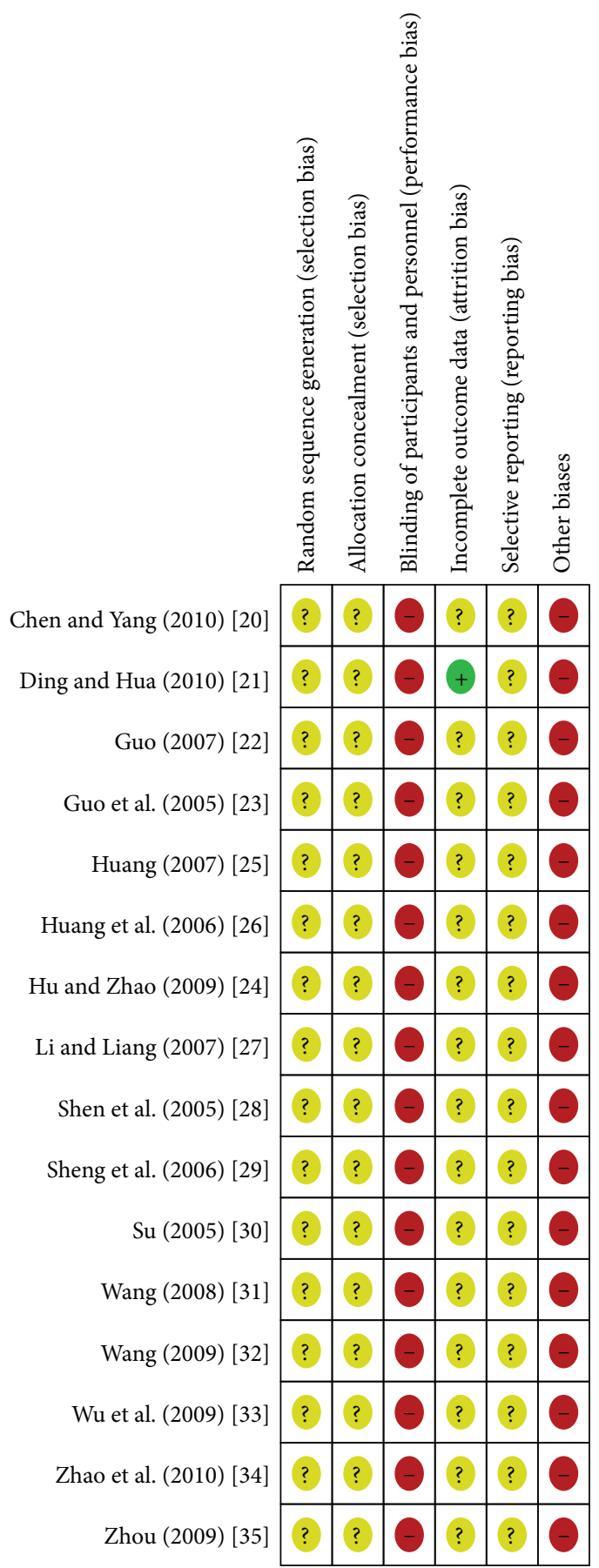

FIGURE 3: Risk of bias summary: reviewing authors' judgements about each risk of bias item for each included study.

3.3. Risk of Bias in Included Studies. The risk of bias of included trials is summarised in Figures 2 and 3. Following the risk of bias components, all trials included were classified as trials with high risk of bias.

3.4. Comparison of Lamivudine Plus OMTR Therapies and Lamivudine Therapies Alone. In this study, the combined 
The incidence of YMDD

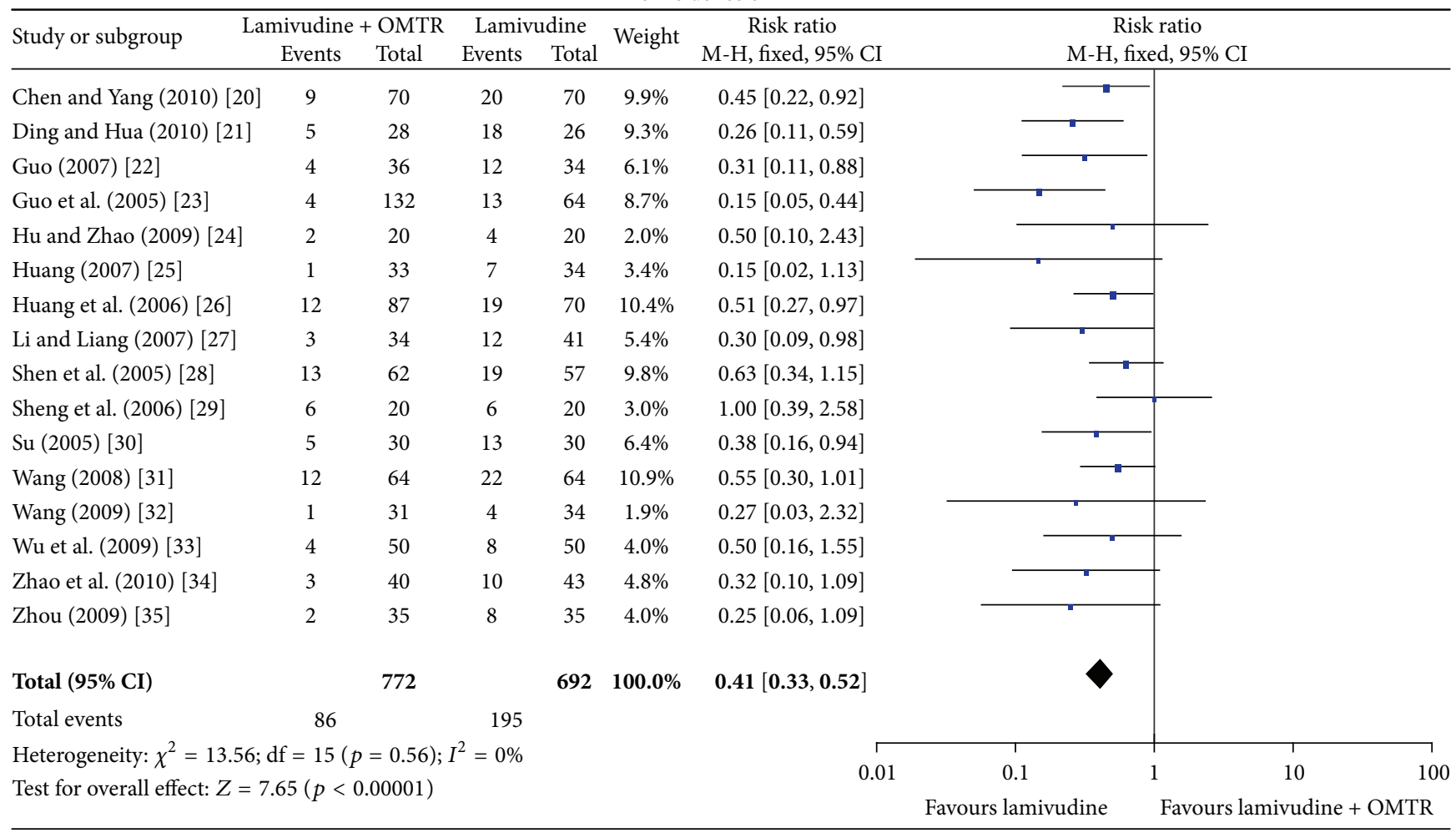

FIGURE 4: The incidence of YMDD mutation: comparison of lamivudine plus OMTR therapies and lamivudine therapy. RR, relative risk; CI, confidence interval; test for heterogeneity: Chi-squared statistic with its degrees of freedom (df) and $p$ value; inconsistency among results: $I^{2}$ test for overall effect; $Z$ statistic with $p$ value.

therapies of lamivudine plus OMTR were superior to lamivudine monotherapy. Patients treated with lamivudine plus OMTR achieved lower incidence of YMDD mutation than patients treated only with lamivudine $11.14 \%(86 / 772)$ versus 28.18\% (195/692); RR: 0.41; 95\% CI: 0.33-0.52; $p<0.05$ (Figure 4). ETVRs were also higher in patients treated with combined therapies compared to the patients treated with lamivudine alone $(86.90 \%$ (690/794) versus $74.68 \%$ (531/711); RR: 1.15 ; 95\% CI: $1.09-1.21 ; p<0.05)$ (Figure 5). Patients treated with combined therapies also achieved significantly higher ALT normalization, HBeAg loss, and HBeAg seroconversion (ALT normalization: $88.74 \%$ (410/462) versus $72.25 \%$ (289/400); RR: 1.24; 95\% CI: $1.16-1.33 ; p<0.05$. HBeAg loss: $49.65 \%$ (358/721) versus $26.49 \%$ (169/638); RR: $1.90 ; 95 \%$ CI: $1.63-2.20 ; p<0.05$. HBeAg seroconversion: $39.49 \%$ (297/752) versus $20.68 \%$ (139/672); RR: 1.94; 95\% CI: $1.63-$ 2.30; $p<0.05$ ) (Figures 5 and 6). In this meta-analysis for the incidence of YMDD mutation, ETVR, ALT normalization, $\mathrm{HBeAg}$ loss, and $\mathrm{HBeAg}$ seroconversion, there was no apparent heterogeneity.

3.5. Safety Profile Evaluation. Four included trials [21, 26, 29, 34] reported side effects. Adverse events were also reported in the included trials (including itch of skin, bellyache, diarrhoea, and fever). The overall adverse events showed no difference in patients treated with lamivudine plus OMTR and in patients treated with lamivudine alone, according to the reports of the included trials.

3.6. Publication Bias. We performed funnel plot analysis for the incidence of YMDD mutation to explore publication bias. All sixteen trials included for a funnel plot analysis of lamivudine plus OMTR therapies versus lamivudine therapy lay within the $95 \% \mathrm{CI}$ line. These results implied the existence of some publication bias.

\section{Discussion}

As new generations of anti-HBV drugs are available, the application of lamivudine was reducing; thus less correlation studies were reported. However, lamivudine is still used in some low-income countries due to the high cost of new antiviral drugs [2]. Lamivudine is an inexpensive agent, but it engenders very high rates of resistance with long-term monotherapy. The resistance generation is closely associated with mutations in the highly conserved YMDD motif [6]. Lamivudine therapy would increase the risk of YMDD mutations 5.23 times higher than the untreated patients. It is notable that YMDD-motif mutation can also occur naturally with a rather high rate about $12.21 \%$ among untreated $\mathrm{CHB}$ patients [36]. The prevalence of drug-resistant mutants in patients is associated with the loss of clinical and virological 
ETVR

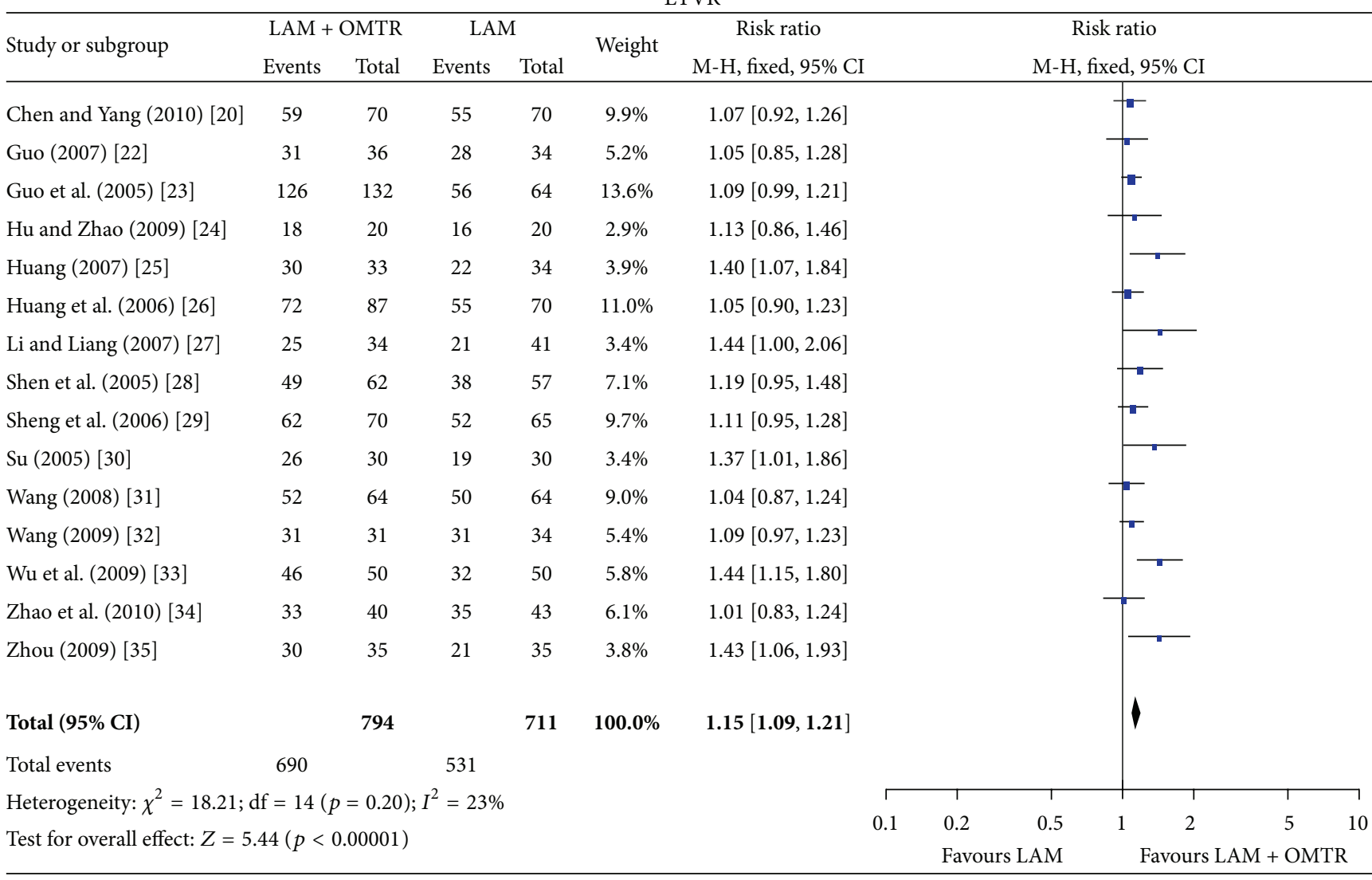

ALT normalization

\begin{tabular}{|c|c|c|c|c|c|c|c|c|c|c|}
\hline \multirow{3}{*}{$\begin{array}{l}\text { Study or subgroup } \\
\text { Chen and Yang (2010) [20] }\end{array}$} & \multicolumn{2}{|c|}{ LAM + OMTR } & \multicolumn{2}{|c|}{ LAM } & \multirow{3}{*}{$\begin{array}{l}\text { Weight } \\
18.4 \%\end{array}$} & \multirow{2}{*}{$\begin{array}{c}\text { Risk ratio } \\
\text { M-H, fixed, 95\% CI }\end{array}$} & \multirow{2}{*}{\multicolumn{3}{|c|}{$\begin{array}{c}\text { Risk ratio } \\
\text { M-H, fixed, 95\% CI }\end{array}$}} & \\
\hline & \multirow{2}{*}{$\begin{array}{c}\text { Events } \\
64\end{array}$} & \multirow{2}{*}{$\begin{array}{c}\text { Total } \\
70\end{array}$} & \multirow{2}{*}{$\begin{array}{c}\text { Events } \\
55\end{array}$} & \multirow{2}{*}{$\begin{array}{c}\text { Total } \\
70\end{array}$} & & & & & & \\
\hline & & & & & & $1.16[1.01,1.34]$ & & & & \\
\hline Guo et al. (2005) [23] & 118 & 132 & 39 & 64 & $17.6 \%$ & $1.47[1.20,1.80]$ & & & & \\
\hline Hu and Zhao (2009) [24] & 18 & 20 & 16 & 20 & $5.3 \%$ & $1.13[0.86,1.46]$ & & & & \\
\hline Huang (2007) [25] & 31 & 33 & 23 & 34 & $7.6 \%$ & $1.39[1.08,1.78]$ & & & & \\
\hline Li and Liang (2007) [27] & 31 & 34 & 35 & 41 & $10.6 \%$ & $1.07[0.91,1.26]$ & & & & \\
\hline Shen et al. (2005) [28] & 47 & 62 & 38 & 57 & $13.2 \%$ & $1.14[0.90,1.43]$ & & & - & \\
\hline $\mathrm{Su}(2005)[30]$ & 27 & 30 & 20 & 30 & $6.7 \%$ & $1.35[1.02,1.79]$ & & & & \\
\hline Wang (2009) [32] & 28 & 31 & 26 & 34 & $8.3 \%$ & $1.18[0.95,1.47]$ & & & & \\
\hline Wu et al. (2009) [33] & 46 & 50 & 37 & 50 & $12.4 \%$ & $1.24[1.03,1.49]$ & & & - & \\
\hline Total (95\% CI) & & 462 & & 400 & $100.0 \%$ & $1.24[1.16,1.33]$ & & & $\gamma$ & \\
\hline Total events & 410 & & 289 & & & & & & & \\
\hline Heterogeneity: $\chi^{2}=9.01 ; \mathrm{d}$ & $f=8(p=$ & $0.34)$ & $=11 \%$ & & & 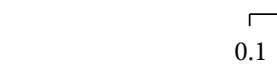 & 0.2 & 0.5 & $\frac{1}{2}$ & $\begin{array}{l}1 \\
5\end{array}$ \\
\hline Test for overall effect: $Z=5$ & $.97(p<$ & $.00001)$ & & & & & Fav & LAM & Favours & + OMTR \\
\hline
\end{tabular}

FIGURE 5: ETVR and ALT normalization: comparison of lamivudine plus OMTR therapies and lamivudine therapy. RR, relative risk; CI, confidence interval; test for heterogeneity: Chi-squared statistic with its degrees of freedom (df) and $p$ value; inconsistency among results: $I^{2}$ test for overall effect; $Z$ statistic with $p$ value. 
HBeAg loss

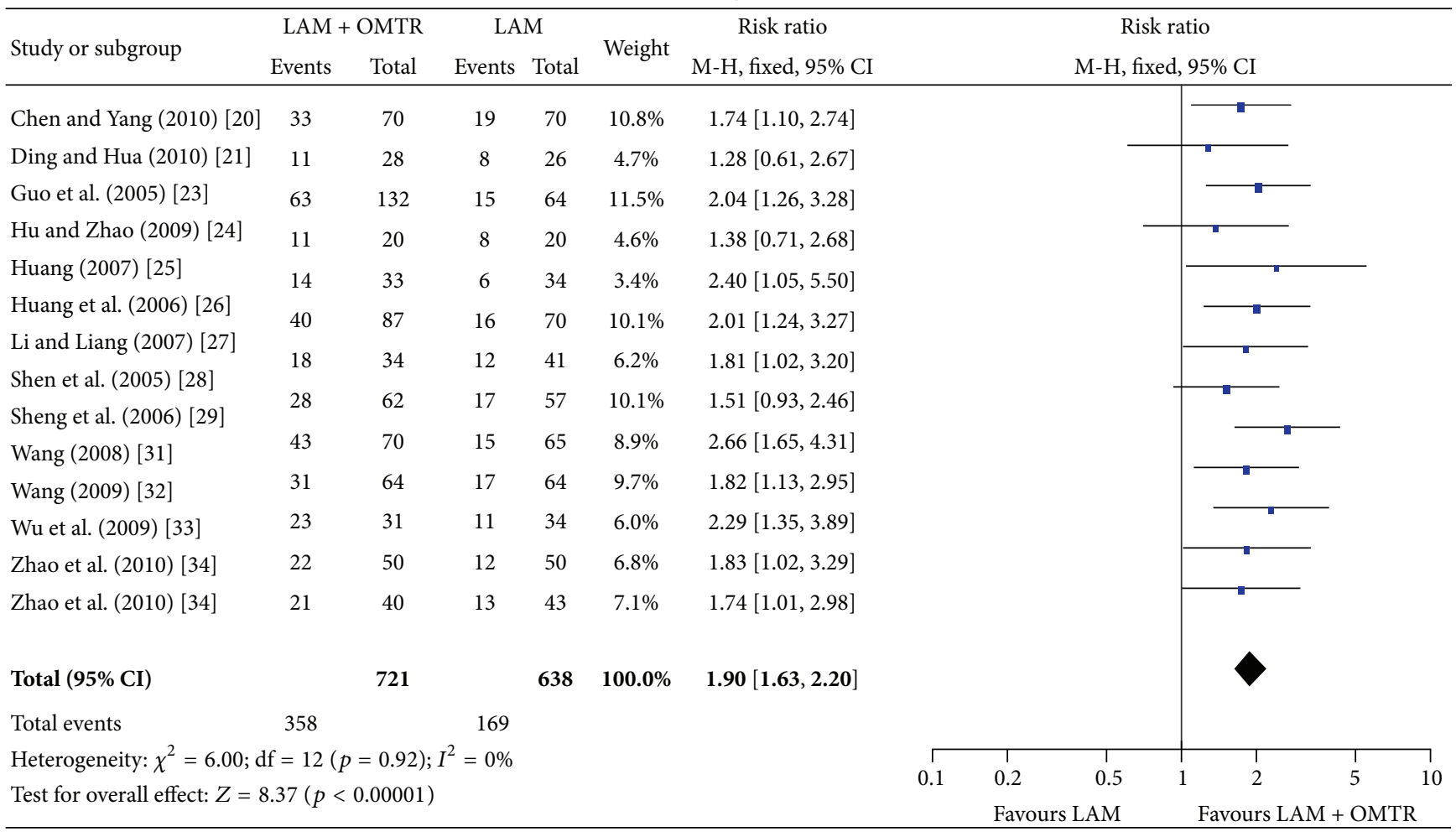

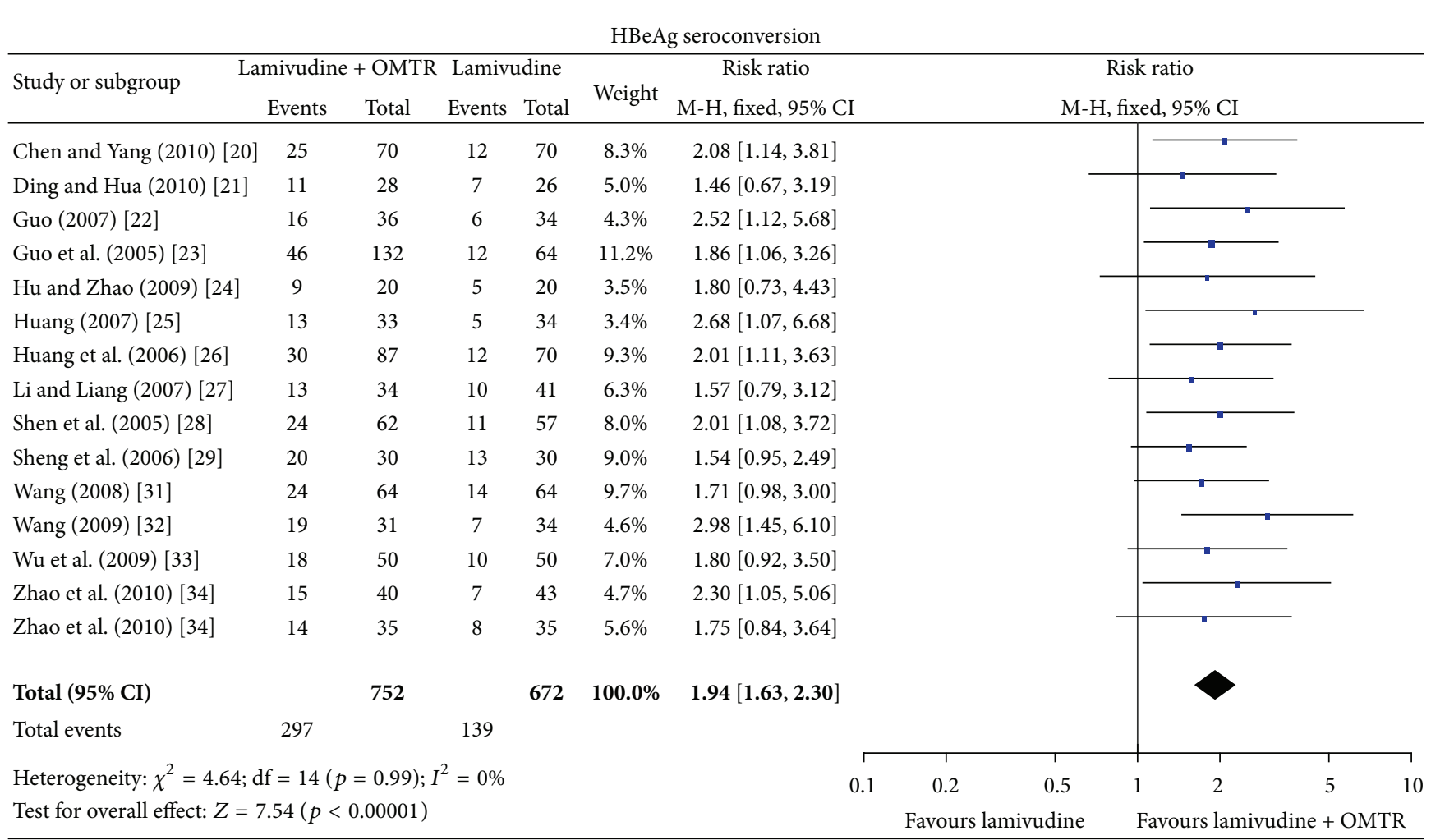

FIgURE 6: HBeAg loss and HBeAg seroconversion: comparison of lamivudine plus OMTR therapies and lamivudine therapy. RR, relative risk; CI, confidence interval; test for heterogeneity: Chi-squared statistic with its degrees of freedom (df) and $p$ value; inconsistency among results: $I^{2}$ test for overall effect; $Z$ statistic with $p$ value. 
benefits and may limit future therapeutic options. So prevention is important for long-term therapeutic efficacy. In successful antiviral therapy of patients, drug combinations can delay or prevent the emergence of drug-resistant mutants.

In this study, we have summarized the available evidence from RCTs comparing lamivudine monotherapy with lamivudine plus OMTR therapies for the treatment of CHB. Our results suggest that combination therapies of lamivudine plus OMTR may achieve significantly lower incidence of YMDD mutations than lamivudine monotherapy. Combination therapies of LAM plus OMTR have also shown superior ETVRs, ALT normalizations, HBeAg loss, and HBeAg seroconversion.

Ideally, drugs used in combination should have different mechanisms of action and act additively or synergistically. Current oral treatments for $\mathrm{CHB}$ are all nucleoside/nucleotide reverse transcriptase inhibitors that inhibit HBV DNA replication by targeting the HBV DNA polymerase. OMTR acts by multiple mechanisms that involve both antiviral and immunomodulatory effects. These include direct antiviral effect, activation of host antiviral enzymes, and stimulation of cellular immune responses against HBVinfected hepatocytes [11-16, 37, 38]. The efficacy of OMTR is bound up with its multiple pharmacological activities. It should be mentioned here that the anti-HBV effect of OMTR is mediated through heat-stress cognate 70 (Hsc70) downregulations (an indirect effect). Hsc70 is a host protein which supports HBV DNA replication [39]. OMTR significantly suppressed HBV de novo synthesis at the reverse transcription stage from pgRNA to DNA and was active against either wild-type HBV or variants resistant to lamivudine, adefovir, and entecavir $[39,40]$. The anti-HBV effect of OMTR was mediated through destabilizing Hsc70 mRNA; Hsc70 mRNA $3^{\prime}$ UTR sequence was the element responsible for the destabilization effect of OMTR [39]. These findings suggested that OMTR therapies are associated with lower incidence of YMDD mutations and are more efficacious in the treatment of $\mathrm{CHB}$ patients when combined with lamivudine.

But it must be noted that this meta-analysis had some limitations. Firstly, the quality of the methodological design of individual studies was not high. Secondly, the asymmetric funnel plot implied that publication biases may occur. Thirdly, the diversity of treatment dose and the small sample number and the lack of long-term follow-ups degraded the validity of the evidence of the clinical trials.

\section{Conclusions}

Combined therapies of lamivudine plus OMTR yielded a lower incidence of YMDD mutation than lamivudine monotherapy. This finding provided some useful information for clinical treatment and future research of YMDD mutation. Considering that this meta-analysis had the limitations in some ways, the exact outcome needs to perform rigorously designed, multicenter, and large randomized controlled trials.

\section{Conflict of Interests}

The authors declare that they have no conflict of interests.

\section{Acknowledgments}

This study was supported by the National Key New Drugs Creation Project, Innovative Drug Research and Development Technology Platform (no. 2012ZX09303009-001), the Specialized Research Fund for the Doctoral Program of Higher Education (no. 20123107120002), and Shanghai Key Laboratory of Clinical TCM Project (no. C10dZ2220200).

\section{References}

[1] European Association for the Study of the Liver, "EASL clinical practice guidelines: management of chronic hepatitis B virus infection," Journal of Hepatology, vol. 57, no. 1, pp. 167-185, 2012.

[2] Y.-F. Liaw, "Antiviral therapy of chronic hepatitis B: opportunities and challenges in Asia," Journal of Hepatology, vol. 51, no. 2, pp. 403-410, 2009.

[3] J. Sun and J. L. Hou, "Management of chronic hepatitis B: experience from China," Journal of Viral Hepatitis, vol. 17, supplement 1, pp. 10-17, 2010.

[4] F. Zoulim and S. Locarnini, "Management of treatment failure in chronic hepatitis B," Journal of Hepatology, vol. 56, supplement 1, pp. S112-S122, 2012.

[5] M. S. Gomes-Gouvêa, A. C. Ferreira, R. Teixeira et al., "HBV carrying drug-resistance mutations in chronically infected treatment-naive patients," Antiviral Therapy, vol. 20, pp. 387$395,2015$.

[6] T. Shaw, A. Bartholomeusz, and S. Locarnini, "HBV drug resistance: mechanisms, detection and interpretation," Journal of Hepatology, vol. 44, no. 3, pp. 593-606, 2006.

[7] J.-X. Yang, B.-M. Liu, X.-G. Li et al., "Profile of HBV antiviral resistance mutations with distinct evolutionary pathways against nucleoside/nucleotide analogue treatment among Chinese chronic hepatitis B patients," Antiviral Therapy, vol. 15, no. 8, pp. 1171-1178, 2010.

[8] D. J. Tenney, S. M. Levine, R. E. Rose et al., "Clinical emergence of entecavir-resistant hepatitis B virus requires additional substitutions in virus already resistant to lamivudine," Antimicrobial Agents and Chemotherapy, vol. 48, no. 9, pp. 3498-3507, 2004.

[9] M. Zhang, G. Ge, Y. Yang et al., "Decreased antigenicity profiles of immune-escaped and drug-resistant hepatitis B surface antigen (HBsAg) double mutants," Virology Journal, vol. 10, article 292, 2013.

[10] J.-H. Yang, H. Zhang, X.-B. Chen, G. Chen, and X. Wang, "Relationship between hepatocellular carcinoma and hepatitis B virus genotype with spontaneous YMDD mutations," World Journal of Gastroenterology, vol. 19, no. 24, pp. 3861-3865, 2013.

[11] S.-L. Wang, N.-L. Yao, W.-L. Lv, and T.-X. Wu, "Kushenin for chronic hepatitis B: a systematic review," Chinese Journal of Evidence-Based Medicine, vol. 8, no. 2, pp. 102-119, 2008.

[12] L. J. Shi, L. Shi, and G. Y. Song, "Review on oxymatrine for liver disease," Modernization of Traditional Chinese Medicine and Materia Medica-World Science and Technology, vol. 16, no. 2, pp. 448-451, 2014.

[13] L.-G. Lu, M.-D. Zeng, Y.-M. Mao et al., "Inhibitory effect of oxymatrine on serum hepatitis B virus DNA in HBV transgenic mice," World Journal of Gastroenterology, vol. 10, no. 8, pp. 11761179, 2004.

[14] W.-S. Xu, K.-K. Zhao, X.-H. Miao et al., "Effect of oxymatrine on the replication cycle of hepatitis B virus in vitro," World Journal of Gastroenterology, vol. 16, no. 16, pp. 2028-2037, 2010. 
[15] L.-G. Lu, M.-D. Zeng, Y.-M. Mao et al., "Oxymatrine therapy for chronic hepatitis B: a randomized double-blind and placebocontrolled multi-center trial," World Journal of Gastroenterology, vol. 9, no. 11, pp. 2480-2483, 2003.

[16] Y.-M. Mao, M.-D. Zeng, L.-G. Lu et al., "Capsule oxymatrine in treatment of hepatic fibrosis due to chronic viral hepatitis: a randomized, double blind, placebo-controlled, multicenter clinical study," World Journal of Gastroenterology, vol. 10, no. 22, pp. 3269-3273, 2004.

[17] C.-L. Lai, J. Dienstag, E. Schiff et al., "Prevalence and clinical correlates of YMDD variants during lamivudine therapy for patients with chronic hepatitis B," Clinical Infectious Diseases, vol. 36, no. 6, pp. 687-696, 2003.

[18] Y. Xia, H. Luo, J. P. Liu, and C. Gluud, "Phyllanthus species versus antiviral drugs for chronic hepatitis B virus infection," The Cochrane Database of Systematic Reviews, vol. 4, Article ID CD009004, 2013.

[19] J. Higgins and S. Green, Eds., Cochrane Handbook for Systematic Reviews of Interventions Version 5.0.2, The Cochrane Colloboration, 2009, http://handbook.cochrane.org/.

[20] Q. Chen and H. F. Yang, "Clinical study of the lamivudine combined with oxymatrine in the treatment of $\mathrm{HBeAg}$ positive chronic hepatitis B patients," Chinese Journal of Integrated Traditional and Western Medicine on Digestion, vol. 18, no. 2, pp. 117-118, 2010.

[21] H. Ding and Z. Hua, "Clinical study of the lamivudine combined with oxymatrine in the treatment of $\mathrm{HBeAg}$ positive chronic hepatitis B patients," Chinese Hepatology, vol. 15, no. 3, pp. 192-193, 2010.

[22] X. L. Guo, "Clinical study of the lamivudine combined with oxymatrine in the treatment of chronic hepatitis B," Chinese Journal of Integrated Traditional and Western Medicine on Digestion, vol. 15, no. 3, pp. 191-192, 2007.

[23] X. F. Guo, Y. Z. Qin, and Y. B. Wang, "Clinical study of the lamivudine combined with oxymatrine in the treatment of chronic hepatitis B," Medical Forum, vol. 9, no. 10, p. 889, 2005.

[24] X. P. Hu and Z. F. Zhao, "Effect of Kushenin combined with lamivudine in treating chronic hepatitis B and its influence on YMDD motif mutation," Journal of Shanxi College of Traditional Chinese Medicine, vol. 10, no. 6, pp. 61-63, 2009.

[25] X. Z. Huang, "Effect of Kushenin combined with lamivudine in treating chronic hepatitis B and its influence on YMDD motif mutation," China Medical Herald, vol. 4, no. 11, pp. 24-25, 2007.

[26] Y. Q. Huang, Z. H. Lin, S. M. Ji, Z. J. Xu, and C. G. Wang, "Clinical study of the lamivudine combined with oxymatrine in the treatment of chronic hepatitis B," Chinese Journal of Infectious Diseases, vol. 24, no. 1, pp. 56-58, 2006.

[27] J. Li and S. R. Liang, "Clinical study of the lamivudine combined with oxymatrine in the treatment of chronic hepatitis B," Tianjin Journal of Traditional Chinese Medicine, vol. 24, no. 2, pp. 107109, 2007.

[28] Y. P. Shen, Y. H. Zhang, C. H. Wang, and L. L. Zhang, "Effect of Kushenin combined with lamivudine in treating chronic hepatitis B and its influence on YMDD motif mutation," Journal of Jiangsu University (Medicine), vol. 15, no. 2, pp. 135-137, 2005.

[29] X. Sheng, J. Fang, and Q. B. Zhan, "Clinical study of the lamivudine combined with oxymatrine in the treatment of chronic hepatitis B," Jiangxi Journal of Traditional Chinese Medicine, vol. 37, no. 287, pp. 26-27, 2006.

[30] G. Y. Su, "Clinical study of the lamivudine combined with oxymatrine in the treatment of chronic hepatitis B," Clinical Medicine, vol. 25, no. 12, pp. 62-64, 2005.
[31] J. F. Wang, "Clinical study of the lamivudine combined with oxymatrine in the treatment of chronic hepatitis B," Journal of Practical Medical Techniques, vol. 15, no. 6, pp. 728-729, 2008.

[32] H. R. Wang, "Clinical study of the lamivudine combined with oxymatrine in the treatment of chronic hepatitis B," Medical Forum, supplement, pp. 22-23, 2009.

[33] D. K. Wu, H. M. Wang, and L. Yang, "Clinical study of the lamivudine combined with oxymatrine in the treatment of chronic hepatitis B," Chinese Journal of Ethnomedicine and Ethnopharmacy, vol. 10, no. 2, pp. 27-28, 2009.

[34] W. L. Zhao, H. Chen, B. C. Wang, and C. Y. Zhang, "Clinical study of the lamivudine combined with oxymatrine in the treatment of chronic hepatitis B," Journal of Yunyang Medical College, vol. 29, no. 3, pp. 270-271, 2010.

[35] X. G. Zhou, "Clinical study of the lamivudine combined with oxymatrine in the treatment of chronic hepatitis B," China Practical Medical, vol. 4, no. 15, pp. 143-144, 2009.

[36] Y. Tan, K. Ding, J. Su et al., "The naturally occurring YMDD mutation among patients chronically infected HBV and untreated with lamivudine: a systematic review and metaanalysis," PLoS ONE, vol. 7, no. 3, Article ID e32789, 2012.

[37] N.-L. Chai, Q. Fu, H. Shi et al., "Oxymatrine liposome attenuates hepatic fibrosis via targeting hepatic stellate cells," World Journal of Gastroenterology, vol. 18, no. 31, pp. 4199-4206, 2012.

[38] X.-B. Gu, X.-J. Yang, Z. Hua et al., "Effect of oxymatrine on specific cytotoxic $\mathrm{T}$ lymphocyte surface programmed death receptor-1 expression in patients with chronic hepatitis B," Chinese Medical Journal, vol. 125, no. 8, pp. 1434-1438, 2012.

[39] Y.-P. Wang, F. Liu, H.-W. He et al., "Heat stress cognate 70 host protein as a potential drug target against drug resistance in hepatitis B virus," Antimicrobial Agents and Chemotherapy, vol. 54, no. 5, pp. 2070-2077, 2010.

[40] Y.-P. Wang, W. Zhao, R. Xue et al., "Oxymatrine inhibits hepatitis B infection with an advantage of overcoming drugresistance," Antiviral Research, vol. 89, no. 3, pp. 227-231, 2011. 


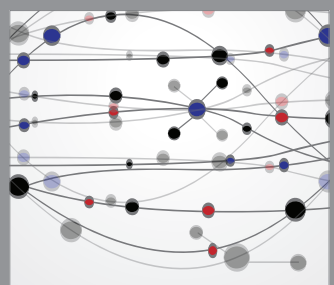

The Scientific World Journal
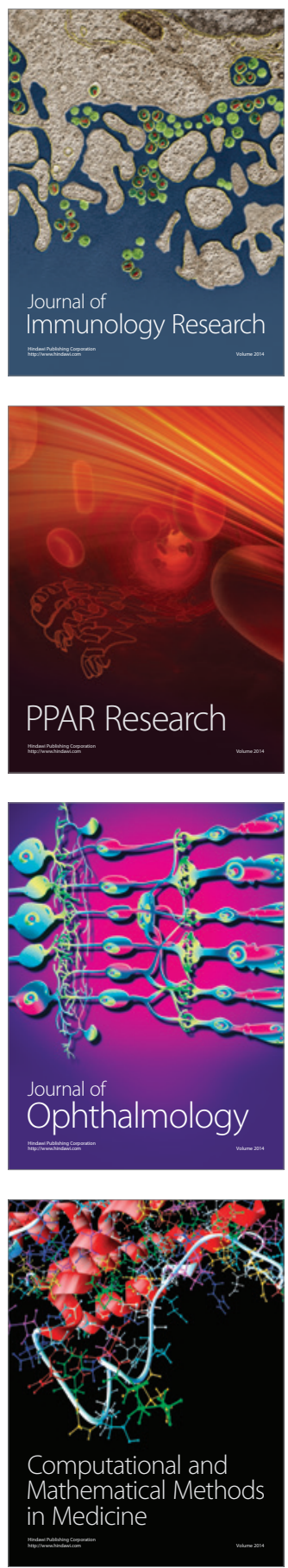

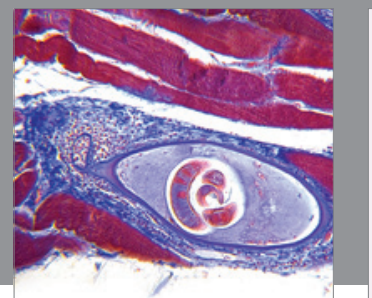

Gastroenterology

Research and Practice
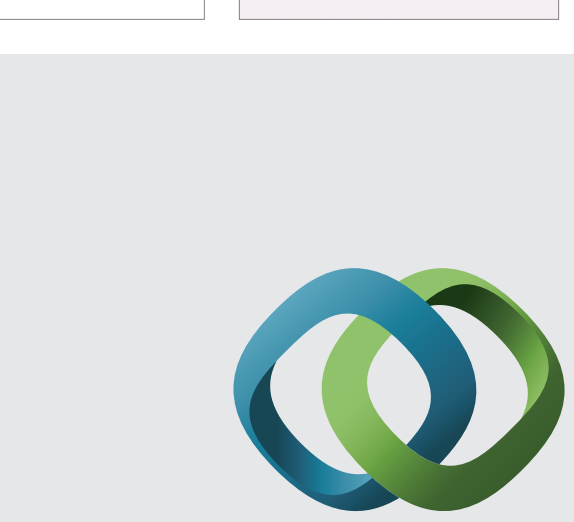

\section{Hindawi}

Submit your manuscripts at

http://www.hindawi.com
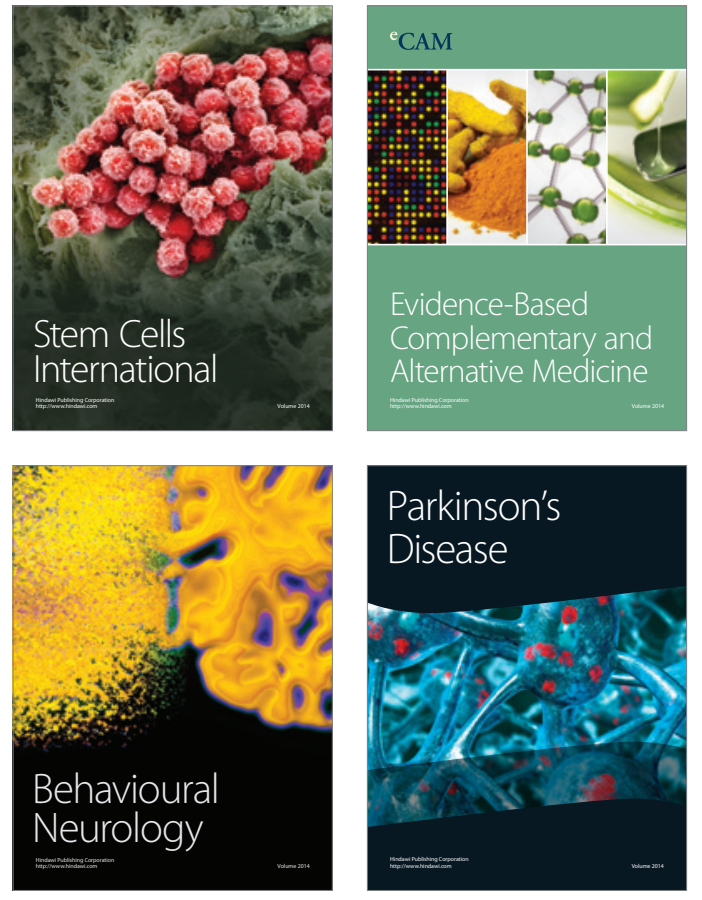
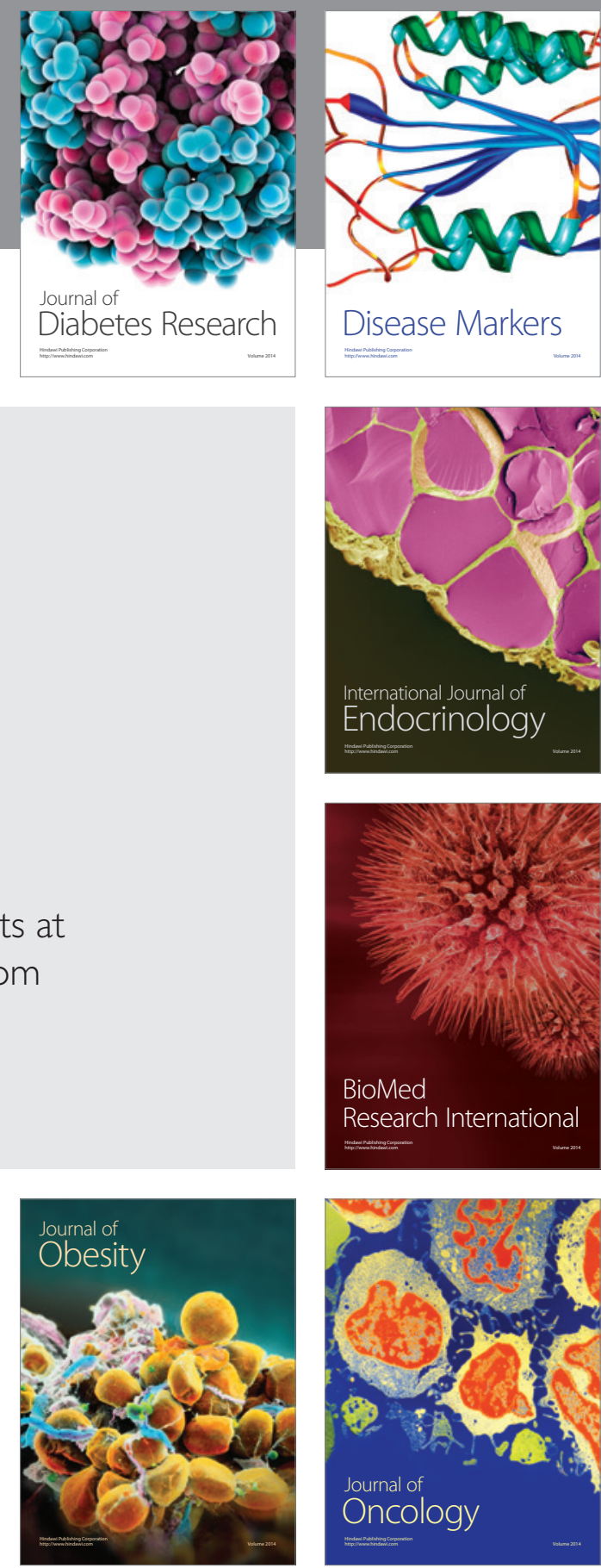

Disease Markers
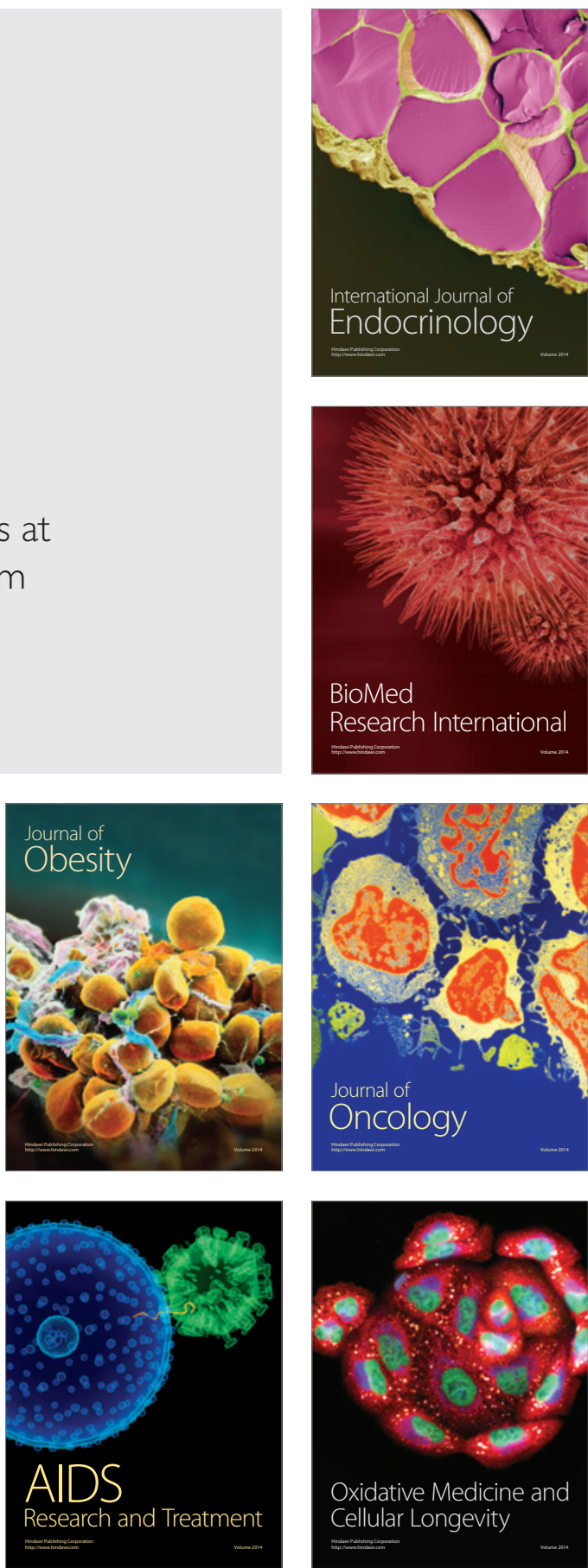